\title{
Research on Performance Evaluation of Urban Public Transport Based on DEA Competing Cross Efficiency
}

\author{
Long CHEN \\ School of Management Science and Engineering \\ Nanjing University of finance and economics \\ E-mail: 2500075750@qq.com
}

\author{
Rong YU \\ School of Management Science and Engineering \\ Nanjing University of finance and economics \\ E-mail: 157868984@qq.com
}

\begin{abstract}
Performance evaluation of urban public transportation enterprises is one of the important measures to promote the priority development of urban public transport, and also is the key basis for the government to fund the city public transportation companies. Traditional DEA cross efficiency evaluation method regard all the decision-making units as an ally or as an enemy at the same time, can not reflect the competition and cooperation between the various bus companies. Therefore, this paper establishes a DEA overlapping efficiency model, all bus company will be divided into several groups through SPSS cluster analysis, to make each company maximize total efficiency all of its sallies meanwhile minimize total efficiency all of its enemies, then we sort and rank performance of bus company based on bus operation index system. The evaluation results are more objective and conducive to the smooth development of urban public transport.
\end{abstract}

Keywords-data envelopment analysis (DEA); overlapping cross efficiency; urban public traffic operation; performance evaluation

\section{INTRODUCTION}

"Give priority to the development of urban public transport" has become the key and optimal choice to relieve the traffic congestion of urban traffic problems. Multiple stakeholders should jointly participate in the process of performance management in the bus industry. Therefore, how to establish a set of effective performance evaluation system of public transportation enterprises and improve the efficiency of the allocation of public transit resources is an urgent task for the development of urban public transport industry in our country at present.

In recent years, domestic and foreign scholars use different methods to evaluate the performance of public transportation management level. Stuart (2000) [1] using structural equation model analyze the relationship between urban public traffic service quality and passenger satisfaction; Laureshyn etc. (2009) [2]. Survey scheme of urban public transport service quality, and study the quantitative evaluation method. Xu Yiqun (2006) [3] research some similar index system by learning from American scholars. With the point of residents of transit trip, He put forward the index system of performance evaluation of city public transport service level suitable for our country national condition; In view of the complex system of multi input and output indexes of the public transportation company, considering the cooperation relationship among the interest parties, the views of the various stakeholders can be integrated to make an effective evaluation.

Data envelopment analysis (DEA) [5], proposed in 1978 by the famous research scholars A.Charnes and W.W.Cooper, is a new field of mathematical economics, management science and other interdisciplinary. The DEA model were widely applied in various fields after being found and it also have a range of applications in research field of performance evaluation of the urban public traffic system. Qiang Cui (2014) [6] using three stage DEA model analyze the production frontier to evaluate the performance of transportation energy efficiency; Lao Y (2009) [7] evaluated the operating performance of bus line in the transit system based on DEA model and geographic information system. The traditional DEA model is too loose on the limit of weight, leading to the weak of distinct ability and the unobjection of weight value, not to say reflect the competition and cooperation between the different DMUs.

There are conflicts of interest and competition of performance evaluation in the urban public transport enterprise operating. Based on the traditional aggressive cross efficiency and kindness type cross efficiency model, this paper construct overlapping efficiency model through cluster analysis to make each DMU maximize total efficiency all of its sallies meanwhile minimize total efficiency all of its enemies. This model can evaluate performance of Nanjing public transport enterprise operating more objectively and effectively, improve the operation efficiency and service quality and provide a scientific basis for performance evaluation.

\section{Performance Evaluation of Bus Enterprise Operation BASED ON DEA MODEL}

\section{A. CCR Model of Urban Public Traffic Company Operating Performance Evaluation Based on the Traditional DEA}

Suppose there are $n$ bus companies (denoted as DMUs), each $D M U_{j}(j=1,2 \cdots n)$ uses $m$ kinds of inputs $X_{i j}(i=1,2, \cdots m)$ to produce $s$ kinds of outputs $Y_{r j}(r=1,2, \cdots s)$. The calculation of the model is the efficiency value of DMU which denoted as $\theta_{d}$. The efficiency value of all decision making units is less than or equal to 1 . DEA uses the following model for evaluating dth DMU's efficiency: 


$$
\begin{gathered}
\theta_{d}=\operatorname{Max} \frac{\sum_{r=1}^{s} u_{d r} y_{r d}}{\sum_{i=1}^{m} v_{d i} x_{i d}} \\
\text { s.t. }\left\{\begin{array}{l}
\frac{\sum_{r=1}^{s} u_{d r} y_{r d}}{\sum_{i=1}^{m} v_{d i} x_{i d}} \leq 1, d=1,2, \cdots n ; i=1,2, \cdots m ; r=1,2, \cdots s \\
u_{d r} \geq 0, v_{d i} \geq 0, \forall r, i
\end{array}\right.
\end{gathered}
$$

The optimum solution for Model (1) $\mathrm{s}\left(\theta_{d}^{*}, u_{d r}^{*}, v_{d i}^{*}\right)$, Obviously, for other decision making units $\mathrm{j}$,we can also obtain the optimum solution $\left(\theta_{j}^{*}, u_{j r}^{*}, v_{j i}^{*}\right)(j=1,2, \cdots n)$.So the cross efficiency of DMU $\mathrm{d}^{\text {th }}$ is:

$$
E_{d}=\frac{1}{n} \frac{\sum_{j=1}^{n} \sum_{r=1}^{s} u_{j r}^{*} y_{r d}}{\sum_{j=1}^{n} \sum_{i=1}^{m} v_{j i}^{*} x_{i d}}
$$

Although the optimal value of the target efficiency of the traditional CCR model is only one. But its optimal weight vector $\left(u_{j r}^{*}, v_{j i}^{*}\right)$ is not the only one, resulting the cross efficiency value definited in the above is not the only.

\section{B. Existing DEA Cross Efficiency Method}

Doyle $J$, Green $\mathrm{R}^{[5]}$ studied the problem of multiple solutions of cross efficiency, and put forward the and benevolent model. In the progressive model, all DMUs are considered to be competitive. An aggressive weight of a DMU is to maximize its efficiency and minimize the efficiency of other DMUs. By contrast, all DMUs are considered to be cooperative in the benevolent model. An benevolent weight of a DMU is to maximize its efficiency and the efficiency of other DMUs at the same time ${ }^{[17]}$.

When DMU dth achieve its efficiency $\theta_{d}^{*}$, the aggressive cross efficiency of DMU kth based on DMU dth is:

$$
\theta_{d k}=\min \sum_{r=1}^{s} u_{r} y_{r k} / \sum_{i=1}^{m} v_{i} x_{i k}
$$

$$
\text { s.t. }\left\{\begin{array}{l}
\sum_{r=1}^{s} u_{r} y_{r j} / \sum_{i=1}^{m} v_{i} x_{i j} \leq 1, j=1,2, \cdots n \\
\sum_{r=1}^{s} u_{r} y_{r d} / \sum_{i=1}^{m} v_{i} x_{i d}=\theta_{d} \\
u_{r} \geq 0, v_{i} \geq 0, \forall i, j
\end{array}\right.
$$

The benevolent cross efficiency of DMU $\mathrm{k}^{\text {th }}$ based on DMU d ${ }^{\text {th }}$ is:

$$
\overline{\boldsymbol{\theta}}_{d k}=\max \sum_{r=1}^{s} u_{r} y_{r k} / \sum_{i=1}^{m} v_{i} x_{i k}
$$

$$
\text { s.t. }\left\{\begin{array}{l}
\sum_{r=1}^{s} u_{r} y_{r j} / \sum_{i=1}^{m} v_{i} x_{i j} \leq 1, j=1,2, \cdots n \\
\sum_{r=1}^{s} u_{r} y_{r d} / \sum_{i=1}^{m} v_{i} x_{i d}=\theta_{d} \\
u_{r} \geq 0, v_{i} \geq 0, \forall i, j
\end{array}\right.
$$

As a result, the average aggressive and benevolent cross efficiency of DMU kth can be expressed as:

$$
E_{k}=\frac{1}{n} \sum_{j=1}^{n} \theta_{j k}
$$

\begin{tabular}{|c|c|c|c|c|c|c|}
\hline & \multicolumn{4}{|c|}{$\begin{array}{c}\text { Preference weights for other } \\
\text { DMUs }\end{array}$} & \multirow{2}{*}{$\begin{array}{c}\text { Cross } \\
\text { efficienc }\end{array}$} \\
\hline & & $D M U_{l}$ & $D M U_{2}$ & $\ldots$ & $D M U_{n}$ & \\
\hline \multirow{4}{*}{$\begin{array}{l}\text { Efficiency } \\
\text { of DMUs }\end{array}$} & $D M U_{I}$ & $E_{l 1}$ & $E_{12}$ & $\ldots$ & $E_{l n}$ & $E_{l}$ \\
\hline & $D M U_{2}$ & $E_{21}$ & $E_{22}$ & $\ldots$ & $E_{2 n}$ & $E_{2}$ \\
\hline & $\vdots$ & $\vdots$ & $\vdots$ & $\ldots$ & $\vdots$ & $\vdots$ \\
\hline & $D M U_{n}$ & $E_{n 1}$ & $E_{n 2}$ & $\ldots$ & $E_{n n}$ & $E_{n}$ \\
\hline
\end{tabular}

(Average aggressive cross efficiency)

$$
\bar{E}_{k}=\frac{1}{n} \sum_{j=1}^{n} \bar{\theta}_{j k}
$$

(Average benevolent cross efficiency)

Tab. 1 shows the above process, when $E_{i j}=\bar{\theta}_{i j}$ or $\theta_{i j}$, the average cross efficiency $E_{i}=\bar{E}_{i}$ or $E_{i}$.

TABLE I. CROSS EFFICIENCY 
From the perspective of self - assessment, CCR model choose the most favorable self preferences to maximize the efficiency of their own. For cross efficiency of evaluation by others, the average value of the preference of all DMUs, is used as a public weight, the efficiency of each DMU under this public weight is referred as cross efficiency. In this way, the cross efficiency can be more effective to avoid the decision maker's behavior preference, and the final evaluation results can be applied to a wider area.

But there are some deficiencies in the two kinds of method above to solving the cross efficiency: Firstly, the classification of all DMUs are too simple, all DMUs are divided into cooperation or competition at the same time which is not consistent with the actual; Secondly, model (3) and model (4) were obtained in conditions to maximize the efficiency of DMU dth, DMU kth may achieve the maximum or minimum efficiency. That is to say, in this case, the weight system is determined by the decision unit $\mathrm{D}$ and $\mathrm{K}$ together and it will change with the change of DMU kth. So formula (5) and formula (6) are not in the same weight system in fact for the average cross efficiency value, so the result is not accurate enough, can not be used effectively.

\section{DEA CROSSEFFICIENCY EVALUATION MODEL SIMULTANEOUSLY CONSIDERING COMPETITION AND COOPERATION OF DMUS}

In the model (3), each DMU needs to satisfy the mutual competition, and each of DMUs in the model (4) is mutually cooperative. But in fact, there will be a more general situation where some DMUs are competitive but meanwhile others are cooperative. Based on the above mentioned situation, this section proposes another method for the evaluation of the overlap efficiency of DEA. First of all, using the method of cluster analysis to determine the mutual DMU is a competitor or partner. Then, through the model (9) and model (10), the average competing cross efficiency is obtained.

\section{A. Urban Public Transport Companies Operating \\ Performance Evaluation Index Selection}

This paper establishes a set of index system with the characteristics of urban public transportation industry (as shown in Tab. 2).

\section{B. SPSS Cluster Analysis}

In this paper, the clustering analysis method is introduced as follows: the sample is n DMUs, the data is selected as the $n \times n$ matrix of Tab. 1. The value of the sample $i$ is the $\mathrm{n}$ dimension vector $E_{i}=\left(E_{i 1}, E_{i 2}, \cdots E_{i n}\right)(i=1,2, \cdots n)$.

We use the hierarchical clustering method to cluster analysis, it need to calculate the distance between each sample (based on the Euclidean distance) $d_{i j}$ and various types of distance (based on the average linkage) $d_{I J}, i$ and $j$ represent two different sample, $I$ and $J$ represent two different classes.

Here, the calculation method of $d_{i j}$ and $d_{I J}$ is as follows:

$$
\begin{gathered}
d_{i j}=\sqrt{\left(E_{i 1}-E_{j 1}\right)^{2}+\left(E_{i 2}-E_{j 2}\right)^{2}+\ldots+\left(E_{i n}-E_{j n}\right)^{2}} \\
d_{I J}=\sum_{i \in I} \sum_{j \in J} d_{i j} / N_{I} N_{J}
\end{gathered}
$$

(in which $N_{I}$ and $N_{J}$ represent the number of samples of class $I$ and $J$ )

Clustering analysis process is: first, we regard $n$ samples as $n$ classes, the closest distance (similar to the greatest extent) of the two clustering is classified as a class, we obtain $n-1$ classes; then we calculate the distance between class and class after polymerization, the two classes of greatest extent will be aggregated into a new class, and merged into the $n-2$, and so on, each polymerization reduce a class. Until the class average distance is greater than the predetermined threshold. In this paper, the clustering process is realized by software SPSS.

\section{DEA Competing Cross Efficiency Model}

By using the method of cluster analysis, all the DMUs are divided into several classes. If all the DMUs are divided into $H$ classes, the set of DMUs can be recorded as $T_{t}(t=1,2, \cdots H)$. If the two decision units belong to the same category, then they are called partners, if they belong to different categories, then they are called competitors. So the following model can be established to maximize the efficiency of all its allies and minimize the efficiency of all its enemies when unit $d\left(d \in T_{t}\right)$ reaches its optimal efficiency $\theta_{d}^{*}:$

$$
\min \sum_{j \neq d, j \in T_{t}} s_{d j}^{C P}-\sum_{j \notin T_{t}} s_{d j}^{C P}
$$

$$
\text { s.t. }\left\{\begin{array}{l}
\sum_{r=1}^{s} u_{r} y_{r j}-\sum_{i=1}^{m} v_{i} x_{i j}+s_{d j}^{C P}=0, j=1,2, \cdots n, j \neq d \\
\sum_{r=1}^{s} u_{r} y_{r d}-\theta_{d}^{*} \sum_{i=1}^{m} v_{i} x_{i d}=0 \\
s_{d j}^{C P} \geq 0, \forall j \\
u_{r} \geq 0, v_{i} \geq 0, \forall i, j
\end{array}\right.
$$

When model (9) obtain the optimal value $h_{d j}^{C P}=\sum_{r=1}^{s} u_{r} y_{r j} / \sum_{i=1}^{m} v_{i} x_{i j}$, it is the cross efficiency of the unit $\mathrm{j}$ relative to unit $\mathrm{d}$ when the competition and cooperation of DMUs are meanwhile considered. Thus, the average competing cross efficiency of unit $\mathrm{j}$ is:

$$
E_{j}^{*}=\frac{1}{n} \sum_{d=1}^{n} h_{d j}^{C P}
$$


The cross efficiency fuse the thought of evaluation by others of traditional cross efficiency model, but all evaluaters are divided into two types: partners who comply with its preference structure and competitors who inconsistent with its preference structure. The advantage of this method is that it can more effectively reflect the different effects of the evaluation of other DMUs in the evaluation process, so the evaluation results are more objective and credible.

\section{Operation Performance Evaluation of Public BUS COMPANY IN NANJING CITY}

\section{A. Public Transportation and Operation Data Collection in Nanjing City}

This paper will use the above average competing cross efficiency model to carry out a case study of 7 bus companies in Nanjing city in 2011.

\section{B. Performance Evaluation Results of Urban Public \\ Transport Companies Based on The DEA Competing Cross Efficiency Model}

Firstly, we operate Tab. 3 through raditional CCR efficiency model (1) and Benevolent cross efficiency modle (3), and obtain their efficiency value and order as shown in Tab. 4, with the average mercy cross efficiency obtained by formula (5).Model (4) can be transformed as follows the linear programming model (10), so as to obtain the Benevolent cross efficiency matrix as shown in Tab. 5.

$$
\begin{gathered}
\min \sum_{j=1}^{n} s_{d j} \\
\text { s.t. }\left\{\begin{array}{l}
\sum_{r=1}^{s} u_{r} y_{r j}-\sum_{i=1}^{m} v_{i} x_{i j}+s_{d j}=0, j=1,2, \cdots n, j \neq d \\
\sum_{r=1} y_{r d}-\theta_{d}^{*} \sum_{i=1}^{m} v_{i} x_{i d}=0 \\
s_{d j} \geq 0, \forall j \\
u_{r} \geq 0, v_{i} \geq 0, \forall i, j
\end{array}\right.
\end{gathered}
$$

The following tab. 4 can see benevolent cross efficiency model can be more effective in the performance evaluation, the benevolent cross efficiency is the mean value of cross efficiency of each DMU in Tab. 5. It can be seen that at this time only the North bus and Pukou passenger is effective, have tallest differentiation degree, but the value of the latter was less than the former, shows that even if everybody take self-interest strategy, will still be less than which fully rational to maximize their own benefits.
TABLE IV. THE EFFICIENCY DATA OF THE TRADITIONAL CCR MODEL AND THE BENEVOLENT CROSS EFFICIENCY MODEL

\begin{tabular}{|ccccc|}
\hline \multirow{2}{*}{ DMU } & \multicolumn{2}{c}{ CCR model } & \multicolumn{2}{c|}{$\begin{array}{c}\text { benevolent cross } \\
\text { efficiency model }\end{array}$} \\
\cline { 2 - 5 } & efficiency & Value order & efficiency & $\begin{array}{c}\text { Value } \\
\text { order }\end{array}$ \\
\hline PNC & 0.9451 & 3 & 0.9186 & 4 \\
\hline North bus & 1.0000 & 1 & 1.0000 & 1 \\
\hline Accor bus & 0.9525 & 2 & 0.8998 & 5 \\
\hline Metro bus & 0.8461 & 4 & 0.8095 & 6 \\
\hline XNP bus & 1.0000 & 1 & 0.9587 & 2 \\
\hline Pukou bus & 1.0000 & 1 & 1.0000 & 1 \\
\hline Liuhe bus & 1.0000 & 1 & 0.9579 & 3 \\
\hline
\end{tabular}

Results in Tab. 5 can be used to obtain cluster analysis of 7 bus companies in Nanjing City. In Tab. 5, the first 2-8 data on behalf of 7 kinds of preference weights (namely decision standard) and the 2-8 line represents 7 samples. Tab. 5 indicates the assignment of 7 samples under 7 criteria. The clustering analysis method described above is used to get the clustering results shown in Fig. 1. Then use the model (10) to solve the average competing cross efficiency of 7 bus companies as shown in Tab. 6.

TABLE V. The Benevolent CRoss EFFicienCy TABLE

\begin{tabular}{|cccccccc|}
\hline$D M U$ & \#1 & $\mathbf{\# 2}$ & $\mathbf{\# 3}$ & $\mathbf{\# 4}$ & $\mathbf{\# 5}$ & $\mathbf{\# 6}$ & \#7 \\
\hline $\mathbf{1}$ & 0.9451 & 1 & 0.7030 & 0.6574 & 0.7107 & 1 & 1 \\
$\mathbf{2}$ & 0.9451 & 1 & 0.9525 & 0.8461 & 1 & 1 & 1 \\
$\mathbf{3}$ & 0.7982 & 1 & 0.9525 & 0.7682 & 1 & 1 & 0.976 \\
$\mathbf{4}$ & 0.9208 & 1 & 0.8467 & 0.8461 & 1 & 1 & 0.7294 \\
$\mathbf{5}$ & 0.931 & 1 & 0.9525 & 0.8461 & 1 & 1 & 1 \\
$\mathbf{6}$ & 0.9451 & 1 & 0.9525 & 0.8461 & 1 & 1 & 1 \\
$\mathbf{7}$ & 0.9451 & 1 & 0.9389 & 0.8313 & 1 & 1 & 1 \\
\hline
\end{tabular}

The \#1, \#2, \#3, \#4, \#5, \#6, \#7 represent PLC, North bus, Accor bus, Metro buses, NXP bus, Pukou bus and Liuhe bus.

TABLE VI. The COMPETING CROSS EFFICIENCY TABLE

\begin{tabular}{|cccccccc|}
\hline DMU & $\mathbf{\# 1}$ & $\mathbf{\# 2}$ & $\mathbf{\# 3}$ & $\mathbf{\# 4}$ & $\mathbf{\# 5}$ & $\mathbf{\# 6}$ & $\mathbf{\# 7}$ \\
\hline $\mathbf{1}$ & 0.9451 & 1 & 0.703 & 0.6574 & 0.7107 & 1 & 1 \\
$\mathbf{2}$ & 0.7725 & 1 & 0.5538 & 0.3774 & 0.483 & 0.672 & 0.4811 \\
$\mathbf{3}$ & 0.7982 & 1 & 0.9525 & 0.7682 & 1 & 1 & 0.976 \\
$\mathbf{4}$ & 0.9208 & 1 & 0.8467 & 0.8461 & 1 & 1 & 0.7294 \\
$\mathbf{5}$ & 0.1734 & 0.326 & 0.579 & 0.347 & 1 & 0.7026 & 0.4842 \\
$\mathbf{6}$ & 0.0453 & 0.1335 & 0.2362 & 0.1732 & 0.4856 & 1 & 1 \\
$\mathbf{7}$ & 0.0723 & 0.2019 & 0.2888 & 0.1595 & 0.2916 & 1 & 1 \\
\hline Mean & 0.5325 & 0.6659 & 0.5943 & 0.4755 & 0.7101 & 0.9107 & 0.8101 \\
value & & & & & & & \\
Order & 6 & 4 & 5 & 7 & 3 & 1 & 2 \\
\hline
\end{tabular}




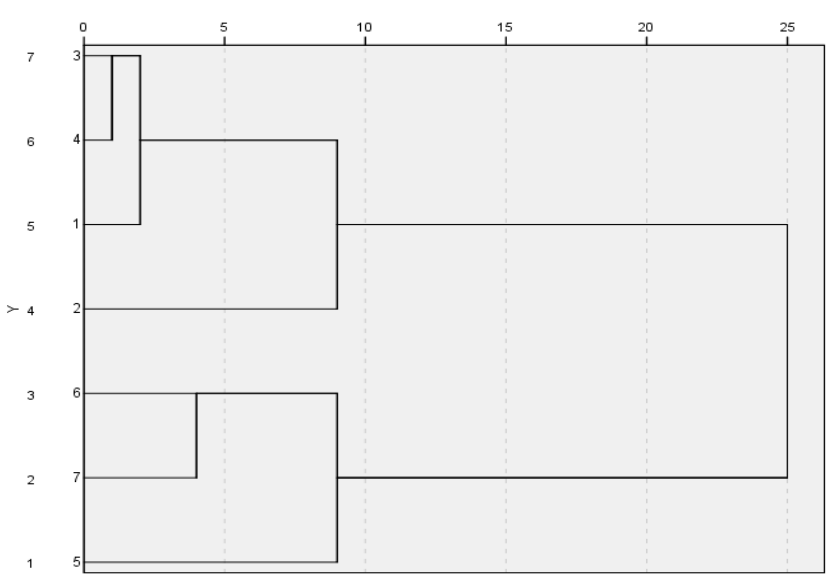

Figure 1. Clustering results

It can be seen that the 7 bus companies can be divided into 3 categories, of which:

First class: PLC, Accor bus, Metro bus;

Second class: North bus;

Third class: Pukou bus, Liuhe bus, XNP bus.

\section{Performance Evaluation Results Analysis}

Tab. 6 shows, operation efficiency evaluation results of Nanjing bus companies determined by the competing cross efficiency is: Pukou bus > Liuhe bus $>$ XNP bus $>$ North bus > Accor bus > PLC > Metro bus. Under this situation, only DEA efficiency value of Liuhe bus is higher than $90 \%$, but there are four companies are effective in CCR model and two in the benevolent cross efficiency model. So overlapping efficiency model can better distinguish the companies of high and low ranking, because it considering the relationship of competition and cooperation between the companies more objectively.

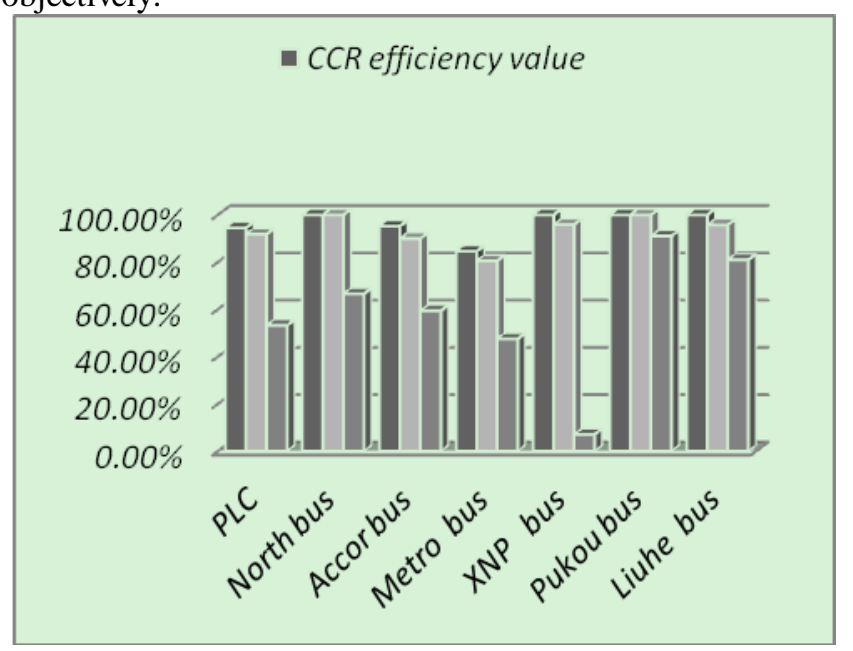

Figure 2. Analysis of calculation results

For each bus company, first of all, the CCR efficiency value is greater than the benevolent cross efficiency, indicating that, even if other DMUs have attitude, evaluate efficiency by others is still lower than self-evaluation efficiencies; secondly, the benevolent cross efficiency is always higher than the overlapping efficiency, illustrate when bus company has cooperation and game, the evaluation results of each company are lower than which always have gracious attitude ; Thirdly, the change of the efficiency value of some bus companies is very obvious like XNP bus while some companies' change is small like Liuhe bus. This is because Liuhe bus has more support of allies than XNP bus, the difference between self-evaluation and others' evaluation is smaller. Finally, some bus companies occupy a better position in what kind of appraisal model, such as Pukou bus, illustrate its input - output conversion efficiency is indeed higher than other companies.

\section{CONCLUDING REMARKS}

It is of great significance to evaluate and rank the efficiency of decision making units in theory and in practice. Is a typical evaluation method, but there is little research on the evaluation of human's choice, this paper puts forward a new method based on the cross efficiency of cooperation and cooperation. The results show that the proposed model can better simulate the competition and cooperation between the DMUs in the real situation, and the performance evaluation results are more consistent with the actual situation. But there are still shortcomings in this paper. In practical application, it is not easy to determine the relationship between the DMUs based on clustering analysis, but should consider the actual situation and the wishes of the decision makers that need to be further improved.

\section{ACKNOWLEDGMENT}

Financial support from the project of natural science research of Jiangsu Province -ChenLong and YuRong, are gratefully acknowledged by the first and second authors, under the contract 14KJB580006.

\section{REFERENCES}

[1] Stuart K R,Mednick M,Bockman J. Structural equation model of customer satisfaction for the New York City subway system[J]. Transportation Research Record 1735, 2000:133-137.

[2] Laureshyn A,Ard H,Jonsson T,Svensson. Application of Automated Video Analysis for Behavioral Studies: Concept and Experience[J]. Intelligent Transport Systems,2009,3 (3):17-22.

[3] Xu Yiqun, Chen Qian. Index system of urban public transport service level [J]. urban traffic, 2006,06:42-46.

[4] Zhang Chao, Yang Xiaoguang, Zhuang Bin. Evaluation model of public traffic line network based on macro simulation [J]. system engineering. 2007 (12).

[5] Charnes A, Cooper WW, Rhodes E. Measuring the efficiency of decision making units. European Journal of Operational Research[M]. 1978,2(6):429-444.

[6] Qiang Cui,Ye Li. The evaluation of transportation energy efficiency: An application of three-stage virtual frontier DEA[J]. Transportation Research Part D: Transport and Environment. 2014,6(29):1-11.

[7] Lao Y,Liu L. Performance evaluation of bus lines with data envelopment analysis and geographic information systems[J]. Computers Environment and Urban Systems. 2009,33:247-255.

[8] Ren Juan. Journal of competitive strategy game DEA recognition of [J]. project management based on the 2015, 29 (4): 102-108. 
[9] Wu Huaqing, Liang Liang, Wu Jie, et al. Analysis and development of.DEA game model [J]. China management science, 2010, 18 (5): 184-192.

[10] Gong Xiaojing, Hong Yue. Supplier selection method based on DEA and game theory $[\mathrm{J}]$. mechanical design and manufacture, 2012 (11): 223-225.
[11] Wu Jie. Data envelopment analysis (DEA) cross efficiency study [D]. University of Science \& Technology China, 2008.

[12] Yang Feng, Xia Joan, Liang Liang. DEA system engineering theory and practice, $[\mathrm{J}]$. system engineering theory and practice, (1): 92-98., 2011,31.

[13] Su Hang. DEA cross efficiency evaluation model study [D]. Jilin University, 2013.

TABLE II. INPUT AND OUTPUT INDEX AND ITS RELATED INDICATORS

\begin{tabular}{|l|l|l|}
\hline \multicolumn{2}{|l|}{ index } \\
\hline \multirow{3}{*}{ input } & $X_{1}$ Fuel cost & Gasoline, diesel and other oil fees consumed by bus operators \\
& $X_{2}$ Labor cost of employees & Company staff salaries, bonuses, medical insurance, etc. \\
& $X_{3}$ Vehicle depreciation expense & Financial performance of vehicle investment recovery \\
& $X_{4}$ Other expenses & Traffic accident loss expenses, insurance expenses, etc. \\
\hline \multirow{3}{*}{ output } & $Y_{1}$ Passenger volume & Total passenger transport \\
& $Y_{2}$ Operating mileage $(10000 \mathrm{~km})$ & The total mileage of the exercise for the purpose of Vehicle operation \\
& $Y_{3}$ Passenger satisfaction & Based on the market questionnaire survey data, use structural equation model (SEM) to measure \\
\hline
\end{tabular}

Note: instructions come from "the people's Republic of China urban construction industry standard of urban public traffic economic and technical indicators calculation method of bus, tram", the Ministry of construction of the people's Republic of China June 4, 1999, approved the implementation.

TABLE III. EPRformance EVAluation Data of NANJing PUblic Transportation Industry

\begin{tabular}{|c|c|c|c|c|c|c|c|}
\hline \multirow{3}{*}{$\begin{array}{l}\text { Nanjing bus } \\
\text { company } \\
(D M U s)\end{array}$} & \multicolumn{4}{|c|}{ input } & \multicolumn{3}{|c|}{ output } \\
\hline & $\begin{array}{c}\text { Fuel cost } \\
(10000 \text { yuan })\end{array}$ & $\begin{array}{c}\text { Labor cost of } \\
\text { employees } \\
\text { (10000 yuan) }\end{array}$ & $\begin{array}{c}\text { Vehicle } \\
\text { depreciation } \\
\text { expense } \\
\text { (10000 yuan) }\end{array}$ & $\begin{array}{l}\text { Other expenses } \\
\text { (10000 yuan) }\end{array}$ & $\begin{array}{c}\text { Passenger } \\
\text { volume } \\
(10000 \text { people })\end{array}$ & $\begin{array}{l}\text { Operating } \\
\text { mileage } \\
(10000 \mathrm{~km})\end{array}$ & $\begin{array}{c}\text { Passenger } \\
\text { satisfaction }\end{array}$ \\
\hline & $X_{1}$ & $X_{2}$ & $X_{3}$ & $X_{4}$ & $Y_{1}$ & $Y_{2}$ & $Y_{3}$ \\
\hline PTC & 32674.73 & 53715.45 & 13470.47 & 3368.88 & 50057.13 & 18581.94 & 60.87 \\
\hline North Bus & 12614.8 & 17051.8 & 4792.8 & 1293.8 & 20852.12 & 7381.98 & 63.77 \\
\hline Accor bus & 5684.55 & 5897.24 & 2360.46 & 850.49 & 7591.78 & 2939.93 & 55.56 \\
\hline Metro bus & 7037.31 & 9621.09 & 2471.73 & 1399.18 & 8511.25 & 4754.78 & 50.48 \\
\hline XNP bus & 2786.8 & 3058.44 & 822.22 & 560.71 & 4364.7 & 1755.61 & 56.68 \\
\hline Pukou bus & 2246.12 & 3119.24 & 620.48 & 288.79 & 3127.54 & 1878.91 & 61.83 \\
\hline Liuhe bus & 3706.32 & 4265.04 & 760.27 & 273.74 & 2947.18 & 2938.86 & 61.93 \\
\hline
\end{tabular}

Note: The data above cited in Jiangsu Province quality and Safety Research Institute "urban public transport management performance evaluation system and the subsidy policy research report. 